\title{
Centenarians and COVID-19: Is There a Link between Longevity and Better Immune Defense?
}

\author{
Paweł Kordowitzki ${ }^{\mathrm{a}, \mathrm{b}}$ \\ anstitute of Animal Reproduction and Food Research of Polish Academy of Sciences, Olsztyn, Poland; \\ ${ }^{b}$ Institute for Veterinary Medicine, Nicolaus Copernicus University, Torun, Poland
}

Dear Editor,

The French nun Sister André who is believed to be the world's second-oldest person was celebrating her 117th birthday on February 11, 2021 after having a SARS-CoV-2 infection. Worldwide, there are several other reports of centenarians who survived COVID-19. This attracted aging and geriatric researchers' attention and prompted questions of how advanced age could be beneficial to COVID-19 patients and why centenarians survive COVID-19. Following the hypothesis "compression of morbidity" centenarians reach extreme old age, due to the fact that their bodies delay or even escape diseases [1]. According to the Robert Koch Institute (February 2021), 46.7\% of German SARS-CoV-2-infected patients aged $80-89$ years died, whereas only $23.3 \%$ of the elderly aged 90 years and older did not survive the pandemic. A possible explanation for this could be inflammaging, which describes the long-term effect upon chronic physiological stimulation of the innate immune system, in other words, the progressive increase in an inflammatory status over years [2]. According to Lio et al. [3], it appears that the mild symptom pattern in centenarians during the COVID-19 pandemic could be correlated to inflammaging, which seems to be a very strik-

karger@karger.com

(c) 2021 S. Karger AG, Basel

www.karger.com/ger

Karger" ing correlation since inflammaging in general is counted as a risk factor for both morbidity and mortality in the elderly. In an Italian report, the correlation between COVID-19 and centenarians was also seen as an interesting link for future research in the geriatric medicine field [4], and even 2 cases of Chinese centenarians from Wuhan who survived the SARS-CoV-2 infection have been provided by the same research group [4]. For patients in extreme old age, it was suggested that IL6 could play a crucial role in contributing to the degree of morbidity and mortality. In a study, where Chinese centenarians were participating, it was found that the polymorphism SNP rs2069837 in IL6 was significantly associated with extreme longevity [5]. Another plausible reason why centenarians overcome COVID-19 better could be due to their characteristic genetic background, namely, how longevity and vulnerability genes are expressed [6-8]. Unique expression patterns of these genes could provide explanation for a superior ability of the centenarians' immune system to defend against SARS$\mathrm{CoV}-2$. Epigenetic changes might also contribute, since centenarians had to go through 2 world wars, hunger, and flu pandemics. These are factors which could have influenced their epigenetic status among others related 
to immune response and could have given the centenarians a selective advantage over younger generations $[9$, 10]. However, like very often in biology and medicine, not all subjects are following the rule. A French report described a higher mortality rate in centenarians (12 patients, median age 101 years) than younger counterparts (309 patients, median age 89 ), but it has to be admitted that the number of subjects in each group was unequal [11]. Interestingly, in another European report, it was revealed that there seems to be a sex difference relevant for the survival rate of patients in very old age, since men older than 90 years appeared to be more resilient than female counterparts of the same age [12]. With regard to the latter mentioned statement, it is noteworthy that Bonafè et al. [13] have reported older men as being more susceptible to the SARS-CoV-2 infection, and they see inflammaging as a negative factor for this. Importantly though, there are more data of SARS-CoV-2-infected centenarians needed to explain clearly the mild symptom pattern in patients of very old age. This letter was aimed to stimulate researchers to perform new interesting studies and to provide a short remark on a timely relevant topic for society, health care, and medicine.

\section{Conflict of Interest}

The author declares no competing financial or nonfinancial interests.

\section{Funding Sources}

P.K. was supported by a special internal fund from the DRI\&P, IAR\&FR PAS, in Olsztyn (3/FBW/2020).

\section{Author Contributions} letter.

P.K. had the conceptual idea of this comment and wrote the

\section{References}

1 Evert J, Lawler E, Bogan H, Perls T. Morbidity profiles of centenarians: survivors, delayers, and escapers. J Gerontol A Biol Sci Med Sci. March 2003;58(3):232-7.

2 Franceschi C, Garagnani P, Parini P, Giuliani C, Santoro A. Inflammaging: a new immune - metabolic viewpoint for age-related diseases. Nat Rev Endocrinol. 2018;14:576-90.

3 Lio D, Scola L, Giarratana RM, Candore G, Colonna-Romano G, Caruso C, et al. SARS CoV2 infection the longevity study perspectives. Ageing Res Rev. 2021;67:101299.

4 Abbatecola AM, Antonelli-Incalzi R. Editorial: COVID-19 spiraling of frailty in older Italian patients. J Nutr Health Aging. 2020; 24(5):453-5.

5 Zeng Y, Nie C, Min J, Liu X, Li M, Chen H, et al. Novel loci and pathways significantly associated with longevity. Sci Rep. 2016 Feb 25; 6:21243.
6 Hook M, Roy S, Williams EG, Bou Sleiman M, Mozhui K, Nelson JF, et al. Genetic cartography of longevity in humans and mice: current landscape and horizons. Biochim Biophys Acta Mol Basis Dis. 2018;1864(9 Pt A):271832.

7 Hartman S, Belsky J. An evolutionary perspective on family studies: differential susceptibility to environmental influences. Fam Process. 2016 Dec;55(4):700-12.

8 Belsky J, Jonassaint C, Pluess M, Stanton M, Brummett B, Williams R. Vulnerability genes or plasticity genes? Mol Psychiatry. 2009 Aug; 14(8):746-54.

9 Scola L, Giarratana RM, Torre S, Argano V, Lio D, Balistreri CR. On the road to accurate biomarkers for cardiometabolic diseases by integrating precision and gender medicine approaches. Int. J Mol Sci. 2019;20(23):6015.
10 Balistreri CR. Anti-inflamm-ageing and/or anti-age-related disease emerging treatments: a historical alchemy or revolutionary effective procedures? Mediators Inflamm. 2018;2018: 3705389 .

11 Couderc A-L, Correard F, Nouguerède E, Berbis J, Rey D, Daumas A, et al. Centenarians in nursing homes during the COVID-19 pandemic. Aging. 2021 Mar 2;13(5):6247-57.

12 Marcon G, Tettamanti M, Capacci G, Fontanel G, Spanò M, Nobili A, et al. COVID-19 mortality in lombardy: the vulnerability of the oldest old and the resilience of male centenarians. Aging. 2020;12(15):15186-95.

13 Bonafè M, Prattichizzo F, Giuliani A, Storci G, Sabbatinelli J, Olivieri F. Inflamm-aging: why older men are the most susceptible to SARS-CoV-2 complicated outcomes. Cytokine Growth Factor Rev. 2020 Jun;53:33-7. 